\title{
APLIKASI MIKROTREMOR UNTUK MIKROZONASI TINGKAT POTENSI BENCANA GEMPA BUMI DI KAMPUS I UNIVERSITAS PGRI YOGYAKARTA
}

\author{
Danang Widyawarman, Ekha Rifki Fauzi \\ Program Sarjana Teknologi Rekayasa Elektro-medis, Fakultas Sains dan Teknologi, Universitas PGRI Yogyakarta \\ E-mail: danangwidyawarman@upy.ac.id
}

\begin{abstract}
Abstrak. Keberadaan Kampus Unit 1 UPY berada di Kabupaten Bantul tempat secara historikal di Bantul pernah terjadi gempa besar tahun 2006 yang mengakibatkan korban jiwa dan kerusakan bangunan dengan skala besar di DIY. Pada kurun waktu 5 tahun terakhir di kawasan unit 1 terjadi pembangunan gedung baru hingga diperlukan penelitian untuk melihat kerentanan terhadap getaran seismik. Dari data pengukuran mikroseismik dapat melihat dan memetakan gedung yang rawan saat terjadi gempabumi agar dapat dilakukan pencegahan dan ketahanan gedung. Pada penelitian ini menggunakan alat Seismometer Lennartz Electronic tipe LE 3D/20s. Data yang telah didapatkan kemudian diolah dengan bantuan software Geopsy untuk memperoleh nilai frekuensi dominan dan amplifikasi dengan metode HVSR. Berdasarkan hasil penelitian diperoleh nilai frekuensi dominan $\left(f_{0}\right)$ di daerah penelitian berkisar $1.27 \mathrm{~Hz}-2.79 \mathrm{~Hz}$, Amplifikasi $\left(\mathrm{A}_{0}\right)$ berkisar antara 1.28 - 2.05, nilai kerentanan seismik (Kg) berkisar antara 1.445 - 2.056, dan nilai Peak Ground Acceleration (PGA) berkisar antara 82.04 gal sampai dengan 236.84 gal. Dari hasil pengolahan data yang diperoleh, dapat disimpulkan bahwa nilai frekuensi dominan yang rendah mengindikasikan adanya lapisan sedimen yang tebal, yang berpengaruh terhadap nilai kerentanan seismik. Untuk nilai PGA dilapisan permukaan masuk ke dalam tingkat resiko sedang dua sampai dengan risiko besar tiga dengan intensitas VII-IX MMI yang sebagian besar berada di area gedung perpustakaan dan auditorium UPY.
\end{abstract}

Kata Kunci: Mikroseismik; HVSR; PGA

\begin{abstract}
The existence of UPY's Unit 1 Campus is in Bantul Regency where historically there was a major earthquake in 2006 that had caused fatalities and large-scale damage to buildings in DIY. During the last 5 years in the area of Unit 1 construction of new buildings has occurred until research is needed to see the vulnerability to seismic vibrations. From the micro-seismic measurement, data can see and map buildings that are vulnerable when an earthquake occurs so that building prevention and resilience can be done. This research uses LE 3D / 20s type Seismometer Electronics Seismometer. The data that has been obtained is then processed with the help of Geopsy software to obtain dominant frequency values and amplification by the HVSR method. Based on the results of the study, the dominant frequency $\left(f_{0}\right)$ in the study area ranged from $1.27 \mathrm{~Hz}-2.79 \mathrm{~Hz}$, Amplification ( $\left.A_{0}\right)$ ranged from 1.28 - 2.05, seismic vulnerability $(\mathrm{Kg})$ ranged from 1.445 - 2.056, and Peak Ground Acceleration (PGA) values ranging from $82.04 \mathrm{gal}$ to $236.84 \mathrm{gal}$. From the results of data processing obtained, it can be concluded that the low dominant frequency value indicates the presence of thick sedimentary layers, which affects the value of seismic vulnerability. For PGA values, the surface layer enters a moderate level of risk, two to three large risks with an intensity of VII-IX MMI, which are mostly in the area of the UPY library and auditorium.
\end{abstract}

Keywords: Mikroseismic; HVSR; PGA

\section{PENDAHULUAN}

Yogyakarta merupakan salah satu propinsi yang masuk ke dalam wilayah dengan tingkat bahaya bencana gempa bumi tinggi, hal ini disebabkan DIY dekat dengan wilayah pertemuan dari Lempeng Eurasia dengan Lempeng Hindia Australia (Brotopuspito, 2006). DIY terletak pada $7^{\circ} 33^{\prime}-8^{\circ} 15^{\prime}$ LS dan $110^{\circ} 5^{\prime}-110^{\circ} 50^{\prime}$ BT yang berbatasan secara langsung dengan gunung berapi vulkanik aktif di sebelah utara dan zona aktif subduksi yang berada di sebelah selatan. Hal tersebut berdampak bagi Yogyakarta dan sekitarnya akan mengalami getaran seismic gempa bumi. Secara historikal kegempaan di DIY, terdapat empat gempa bumi dengan kekuatan magnitudo yang besar dan merusak sifatnya, gempa tersebut diperoleh dari aktivitas tektonik di zona aktif subduksi pada tahun 1867, 1943, 1981, dan 2006 (Setiyono, 2018). 
Tanggal 27 Mei 2006 terjadi gempabumi dengan kekuatan 5.9 Magnitudo di wiliayah Bantul, Daerah Istimewa Yogyakarta yang menyebabkan korban meninggal dunia dan luka-luka disertai kerusakan bangunan (Haifani, 2008). Berdasarkan penelitian dari episentrum gempa bumi dicurigai berlokasi kurang lebih sekitar $10 \mathrm{~km}$ sebelah timur Bantul yang berasosiasi terjadinya sesar Opak (C. Sulaeman, L. Cendekia Dewi, 2008). Kerusakan dari dampak gempa bumi tidak hanya disebabkan besarnya kekuatan getaran gempa, melainkan juga disebabkan dari geologi suatu daerahnya (Daryono, Sutikno, 2009). Suatu daerah rawan dari kerusakan dari gempa bumi terjadi pada wilayah yang memiliki sedimen lunak dan tebal yang berada pada bedrock yang ada pada tingkat keras (A. Wulandari, S. Suharso, R. Rustadi, 2016).

Selain gempabumi di Yogyakarta, gempabumi yang mengakibatkan kerusakan parah juga terjadi di Kabupaten Lombok Timur pada tahun 2018 dengan kekuatan 6.4 Magnitudo dan 7 Magnitudo. Kerusakan parah terjadi di tiga Kabupaten yang yang lokasinya jauh dari episentrum genpabumi, kejadian ini membuktikan bahwa potensi kerusakan infrastruktur bangunan tidak hanya dipengaruhi oleh besarnya jarak dan sumber gempa, tetapi lebih pada efek tapak lokal lokasi daerah setempat. Berdasarkan penelitian yang dilakukan daerah dengan dominasi lapisan sedimen yang lunak rentan terhadap deformasi tanah yang diakibatkan oleh gempabumi (Hakim dkk., 2019).

Karakteristik dari Kabupaten Bantul berdasarkan penelitian terdapat kerapatan kontur jarang dan kerapatan kontur rapat (dominan), bentuk lereng palanar, elevasi 0-125 m dengan geomorfologi dataran dengan relief halus serta bentuk lahan di dominasi fluvio volcanic, dan fluvio marine (Gunawan dan Khadiyanto, 2012).

Kawasan Kampus Unit 1 Universitas PGRI Yogyakarta berada di Kecamatan Kasihan, Kabupaten Bantul, DIY. Pada kawasan unit 1 terdapat pembangunan gedung-gedung baru dalam kurun waktu 5 tahun terakhir. Berdasarkan hal tersebut, perlu adanya penelitian mengenai indeks kerentanan seismik dengan metode pengukuran mikrozonasi menggunakan data mikroseismik untuk mengetahui tingkat potensi bahaya gempabumi pada area Kampus Unit 1 Universitas PGRI Yogyakarta. Kelebihan metode ini dapat mengetahui peta persebaran tingkat kerentanan area terhadap bencana gempa bumi mengingat jika kawasan tersebut adalah area publik untuk aktivitas pendidikan.

\section{TINJAUAN PUSTAKA}

\section{Mikrotremor}

Mikrotremor adalah getaran tanah yang sangat minim dengan intensitas yang terus menerus dan ditimbulkan dari berbagai macam sumber getaran, diantaranya berasal dari aktivitas mesin pabrik, lalu lintas kendaraan, pembangunan kontruksi, dan sebagainya (Kanai, 1983). Mikrotremor di definisikan sebagai suatu getaran harmonik alami dari tanah yang dapat terjadi secara kontinyu, yang terjebak pada lapisan sedimen, kemudian terpantulkan dari adanya batas lapisan dengan adanya frekuensi yang statis, yang disebabkan dari getaran yang sangat kecil yang beraada di bawah permukaan tanah dan aktivitas alami lainnya (Zona dkk., n.d.).

Mirzaoglu dan Dykmen (2003) mengatakan bahwa mikrotremor (ambient noise) ialah suatu getaran tanah dengan parameter amplitude pergeseran sekitar 0,1-1 mikron dan amplitude kecepatan sebesar $0,001-0,01 \mathrm{~cm} /$ detik yang dapat di deteksi dengan menggunakan seismograf. Mikrotremor dapat dibedakan menjadi dua macam yang terletak pada jarak periodenya. Pertama yaitu mikrotremor dengan periode pendek dengan nilai di bawah satu detik, nilai ini menunjukkan struktur bawah permukaan dengan nilai ketebalan beberapa puluh meter yang termasuk kategori dangkal. Sumber dari getaran mikrotremor dengan periode pendek dapat berasal dari berbagai kegiatan manusia, antara lain aktivitas pabrik, lalu lintas kendaraan di jalan, dan sebagainya. Untuk mikrotremor dengan periode lebih dari satu detik, hal ini menunjukkan hubungannya dengan struktur tanah yang lebih dalam (Hidayat dkk., 2017).

\section{HVSR (Horizontal to Vertical Spectral Ratio)}

Metode Horizontal to Vertical Spectral Ratio ialah suatu metode dengan cara membandingkan spectrum dari komponen horizontal terhadap komponen vertical dari gelombang mikrotremor. Pada miktrotremor sendiri terdiri dari berbagai 
gelombang Rayleigh, yang diperkirakan jika periode puncak perbandingan dari $\mathrm{H} / \mathrm{V}$ mikrotremor telah menunjukkan pondasi dasar dari periode gelombang $S$ (Zona dkk., n.d.). Prinsip cara kerja dari metode HVSR dengan menggunakan rekaman gelombang seismik (baik pasif maupun aktif). Ada dua parameter yang terpenting didapatkan dari hasil metode tersebut, yaitu Amplifikasi (Ao) dan Frekuensi Dominan (fo). Parameter ini pada prinsipnya ialah penerapan dari karakterisasi geologi. Langkah dari pengolahan metode ini, yaitu:

a. Sensor seismometr akan merekam getaran

b. Ada time series data pada setiap komponen. Pada langkah ini dilaksanakan pemotongan dari sinyal ambient, agar dapat dianalisis dan diolah pada langkah selanjutnya.

c. Spektrum dari fourier didapatkan dengan cara melaksanakan transformasi fourier pada setiap komponen (vertical, N-S, dan E-W).

d. Sebagian rata-rata dari dua spectrum horizontal dikalkulasi kemudian hasilnya dibagi dengan spectrum vertikalnya sehingga diperoleh sebuah kurva HVSR dengan nilai fo dan $A o$

\section{Transformasi Fourier}

Transformasi fourier pada mikroseismik merupakan suatu metode yang paling sering dipergunakan untuk analisis sinyal karena besaran yang menentukan suatu sinyal adalah dalam domain frekuensi. Sedangkan kumpulan dari gelombang harmonik sinusoidal disebut juga sebagai Deret Fourier. Pada prinsip Transformasi Fourier dipergunakan dalam rangka mengubah data yang awalnya dalam domain waktu ke dalam domain frekuensi. Hal tersebut diperlihatkan dalam persamaan, dibawah ini:

$F(w)=\int_{-\infty}^{\infty} f(t)^{-i w t} d t$

$\mathrm{F}(\mathrm{w})$ yaitu sebagai bentuk dari transforamosi fourier dari $f(t)$. Pada transformasi Faurier dapat dikalkulasi lebih cepat dengan menggunakan FFT (Fast Fourier Transform) dengan komputasi digital.

\section{Frekuensi Dominan (fo)}

Dari pengolahan data HVSR didapatkan nilai frekuensi dominan yang menginterpretasikan frekuensi alami yang ada di daerah tersebut. Hal yang demikian mengatakan jika apabila terjadi suatu gempabumi ataupun gangguan getaran yang mempunyai frekuensi yang sama dengan frekuensi dominan, sehingga terjadi resonansi dengan berdampak amplifikasi gelombang seismik pada daerah tersebut. Nilai dari frekeunsi dominan pada suatu daerah berdasarkan dari Mucciarelli dan Gallipoli dengan dukungan dari berbagai faktor, ialah ketebalan pada lapisan lapuk dan kecepatan rata-rata pada bawah permukaan (Vs), maka di rumuskan, antara lain (Mucciarelli, 2015):

$f o=\frac{V s}{4 H}$

pada persamaan diatas, fo merupakan frekuensi dominan, Vs ialah nilai dari rata-rata dari kecepatan gelombang geser dengan kedalaman hingga 30 meter dari permukaan, sedangkan $\mathrm{H}$ yaitu ketebalan lapisan lapuk.

\section{Amplifikasi (Ao)}

Amplifikasi adalah perbesaran dari gelombang seismik yang terjadi akibat adanya perbedaan antara lapisan yang kontras, atau gelombang seismik akan mengalami perbesaran, ketika merambat dari medium satu ke medium lainnya yang lebih lunak dengan membandingkan medium pertama sebagai pembanding pertamanya (Zona dkk., n.d.). Semakin tinggi nilai penguatan (amplifikasi) tanah sebanding dengan nilai kontras impedansi lapisan permukaan dengan lapisan yang ada dibawahnya. Jika nilai perbandingan dari kontras impedansi lapisan tinggi, maka nilai faktor penguatannya juga tinggi, nilai tersebut berlaku untuk sebaliknya (Nakamura, 2000).

Nilai dari perbandingan spektral horizontal dan vertikal $(\mathrm{H} / \mathrm{V})$ berbanding lurus dengan nilai amplifikasi. Nilai dari amplifikasi dapat mengalami penambahan, apabila suatu batuan mengalami deformasi (pelipatan, pesesaran, atau pelapukan) yang dapat mengubah sifat fisik dari batuan. Pada batuan yang sama, nilai dari amplifikasi dapat bervariasi tergantung dari deformasi dan pelapukan pada batuan tersebut (Marjiyono, 2010).

Nilai amplifikasi (Ao) untuk gelombang seismik dapat disebabkan saat suatu benda yang mempunyai frekuensi, kemudian diberi ganguan dengan gelombang lain yang juga memiliki frekuensi sama. Amplifikasi gelombang gempa akan terjadi pada saat gelombang merambat ke atas permukaan tanah dengan nilai frekuensi dominan (fo) tanah tersebut sama dengan nilai frekuensi gempabumi. 
Amplifikasi ialah suatu kejadian atau peristiwa dari penguatan suatu gelombang saat melewati medium tertentu. Perbandingan diantara karakteristik dari sinyal horizontal terhadap sinyal vertikal memiliki ${ }_{a}$ perbandingan lurus dengan penguatan dari gelombang ketika melalui suatu medium tersebut.

\section{Nilai Kerentanan $(\mathrm{Kg})$}

Parameter yang diperhitungkan pada pengukuran mikroseismik pada mikrozonasi gempa ialah indeks kerentanan seismik $(K g)$. Pada indeks kerentanan pada suatu daerah mengindikasikan dari level kerentanan lapisan tanah yang telah mengalami deformasi yang diakibatkan dari gempa bumi. Nilai dari kerentanan $(K g)$ bisa diperoleh dengan persamaan:

$K g=\frac{A o^{2}}{f o}$

Ao merupakan suatu amplitude (faktor amplifikasi) dan fo merupakan frekuensi natural. Nilai kerentanan yang tinggi atau besar sering ditemukan pada lapisan tanah yang merupakan batuan sedimen yang lunak. Nilai kerentanan yang tinggi menyatakan jika wilayah tersebut masuk kategori rentan terhadap gempa bumi. Sebaliknya jika nilai kerentanan kecil sering terjadi pada tanah dengan batuan yang mempunyai susunan kuat dan stabil. Maka saat terjadi gempa, wilayah tersebut hanya terdampak guncangan kecil (Tanjung dkk., 2019).

\section{Peak Ground Acceleration (PGA)}

Peak Ground Acceleration didefinisikan sebagai nilai percepatan getaran tanah maksimum yang pernah terjadi di suatu daerah, dimana percepatan tersebut terjadi akibat gelombang gempabumi. Nilai percepatan getaran tanah yang terjadi akibat gelombang seismik dipengaruhi oleh gelombang seismik yang merambat pada suatu tanah dan karakteristik lapisan tanah suatu daerah.

Metode untuk menghitung PGA di lapisan tanah permukaan $\left(\alpha_{a}\right)$ dengan metode Kanai (Kanai, 1966 dalam Kirbani dkk., 2006). Metode Kanai menggunakan parameter magnitude gempabumi, jarak hiposenter dengan titik pengukuran, dan nilai dari periode dominan tanah. Rumus yang digunakan untuk menghitung nilai $\alpha_{a}$ di lapisan tanah permukaan menggunakan metode Kanai yang di tunjukkan oleh persamaan di bawah ini. $\alpha_{a}=b 1\left[10^{\left(b_{2} M_{s}-1.66+\left(\frac{3.6}{R}\right) \log R-1,67+\frac{1.83}{R}\right)}\right]$

dengan :

Peak Ground Acceleration dengan satuan dalam gal

$b_{1}=\frac{5}{\sqrt{T}}$

$T=$ Nilai periode dominan tanah

$b_{2}=0,61$

$M_{s}=$ Nilai magnitudo gelombang permukaan

$=-8.545+1.201 \mathrm{mb}$

$M_{b}=$ Magnitudo gelombang badan

$R=$ Jarak hiposenter ke titik pengamat

\section{METODOLOGI}

Pengambilan data mikrotremor dilaksanakan di Kawasan Kampus Unit 1 Universitas PGRI Yogyakarta, Kecamatan Kasihan, Kabupaten Bantul, Daerah Istimewa Yogyakata. Data yang diperoleh dari hasil pengukuran di 14 titik dengan rentang jarak 15 - 20 meter. Pada penelitian ini menggunakan alat seismometer Lennartz Electronic tipe LE 3D/20s. Data mikrotremor yang diperoleh adalah data mikrotremor single station berupa sinyal dalam 3 komponen yakni horizontal timurbarat (E-W), komponen horizontal utara-selatan (NS), dan vertikal (Z).

Waktu yang dibutuhkan pada tiap titik rekaman ialah 20-30 menit. Data yang diperoleh dari pengukuran berupa data time series, artinya data pengukuran masih dalam domain waktu. Sinyal yang diperoleh dari pengukuran terdiri dari sinyal transien dan sinyal stasioner. Dalam mikrotremor sinyal yang dibutuhkan adalah sinyal stasioner yakni sinyal yang memiliki amplitudo yang sama dan tidak bervariasi terhadap waktu. Data yang diperoleh berupa nilai frekuensi dominan dan amplitudonya secara maksimum yang diolah dengan software Geopsy dengan proses analysis HVSR. Peta desain survey pada penelitian ini dapat ditampilkan dibawah ini: 


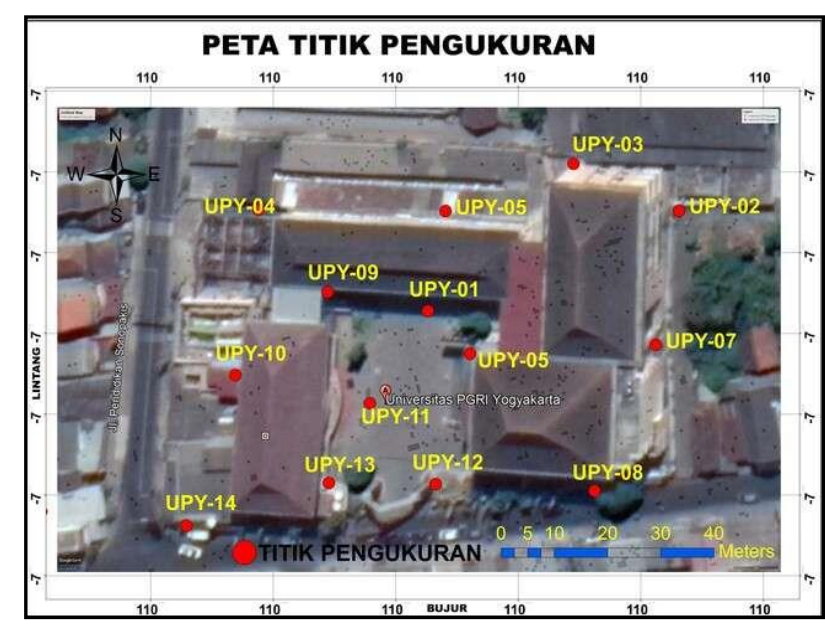

Gambar 1. Peta titik pengukuran

Pada proses penelitian di mulai dengan mempelajari studi literature, perencanaan akuisisi data, analisis, pengolahan, dan menarik kesimpulan. Pada proses pengolahan sinyal pada software Geopsy dilakukan koreksi baseline untuk menghilangkan trendline dari data yang disebabkan oleh noise dengan frekuensi sangat rendah. Koreksi baseline bertujuan untuk membawa sinyal agar berosilasi pada sumbu seimbang yaitu pada sumbu $\mathrm{y}=0$, sehingga hasil dari puncak FFT tidak didominasi oleh frekuensi nol hertz dan agar nilai data amplitudo maksimum dan minimum yang diolah simetri. Tahap selanjutnya dilakukan windowing untuk pemilihan sinyal yang bersifat stasioner dengan menghilangkan sinyal transien. Pada tahap windowing beberapa data dipilih secara manual dan dapat juga dilakukan secara otomatis oleh program. Pemilihan window ini didasarkan pada sinyal pada kawasan waktu yang paling stasioner yang nantinya akan di transformasi fourier ke kawasan frekuensi.

Pada proses pengolahan sinyal pada software Geopsy dilakukan koreksi baseline untuk menghilangkan trendline dari data yang disebabkan oleh noise dengan frekuensi sangat rendah. Koreksi baseline bertujuan untuk membawa sinyal agar berosilasi pada sumbu seimbang yaitu pada sumbu $y=0$, sehingga hasil dari puncak FFT tidak didominasi oleh frekuensi nol hertz dan agar nilai data amplitudo maksimum dan minimum yang diolah simetri. Tahap selanjutnya dilakukan windowing untuk pemilihan sinyal yang bersifat stasioner dengan menghilangkan sinyal transien. Pada tahap windowing beberapa data dipilih secara manual dan dapat juga dilakukan secara otomatis oleh program. Pemilihan window ini didasarkan pada sinyal pada kawasan waktu yang paling stasioner yang nantinya akan di transformasi fourier ke kawasan frekuensi. Setelah dari proses windowing selesai, maka tiga komponen sinyal yang terdiri komponen Horizontal (East-West), Horizontal (North-South), dan Vertikal (Z). akan di analisis dengan metode HVSR.

Setelah proses analisis selesai, akan didapatkan nilai fo (frekuensi dominan) dan Ao (amplifikasi). Nilai dari kerentanan seismic $(\mathrm{kg})$ bisa dicari dengan membagi dari nilai amplitude maksimum kuadrat terhadap nilai frekuensi dominannya. Nilai PGA dilapisan permukaan dapatkan dengan metode Kanai. Diagram alir dari penelitian dapat dilihat dibawah ini:

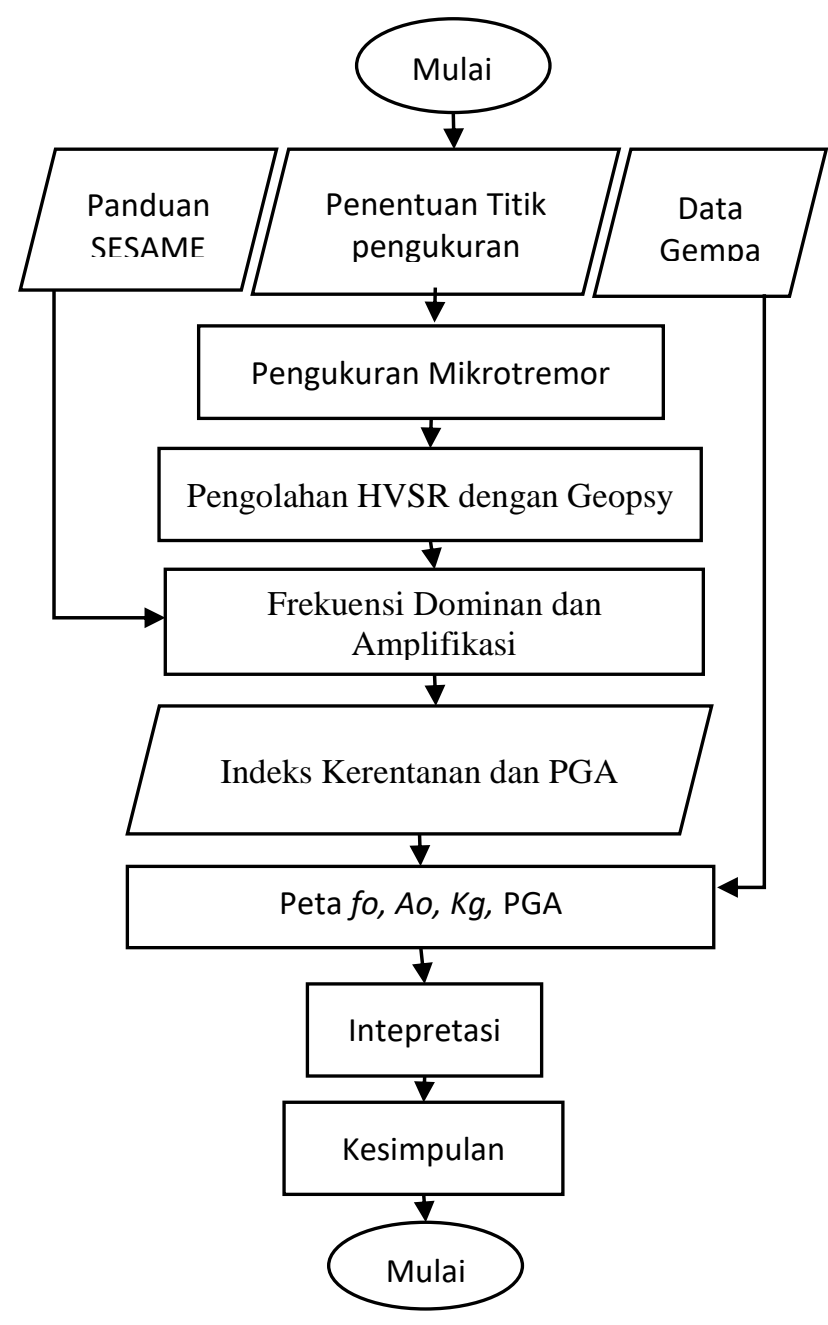

Gambar 2. Diagram Alir Penelitian

\section{HASIL DAN PEMBAHASAN}

Hasil dari penelitian didapatkan nilai frekuensi dominan $\left(f_{o}\right)$ dan amplifikasi $\left(A_{o}\right)$ dari 14 titik pengukuran di Kampus I Universitas PGRI Yogyakarta. Nilai frekuensi dominan $\left(f_{0}\right)$ dan 
amplifikasi $\left(A_{o}\right)$ diperoleh dari kurva HVSR (Horizontal to Vertical Spectral Ratio) yang kemudian digunakan untuk menghitung indeks kerentanan seismik $\left(K_{g}\right)$ dan nilai percepatan getaran tanah maksimum (PGA). Kurva HVSR yang diperoleh dari pengolahan menggunakan Sofware GEOPSY, selanjutnya di analisis dari dua kriteria kurva HVSR yang dikemukakan oleh (Sesame, 2004). Analisis yang digunakan berdasarkan kriteria kurva HVSR yang reliable dan berdasarkan kriteria kurva HVSR dengan puncak yang jelas (clear peak) yang dikemukakan oleh (Sesame, 2004). Berdasarkan analisis kurva HVSR diperoleh 14 titik pengukuran yang menghasilkan kurva HVSR yang reliable dan 8 titik yang masuk kedalam 4 kriteria untuk kriteria dengan puncak yang jelas.

\section{Frekuensi Dominan (fo)}

Nilai frekuensi dominan diperoleh dari hasil kurva HVSR, yang selanjutnya dibuat peta kontur persebaran frekuensi dominan. Nilai frekuensi dominan dapat digunakan untuk perncanaan bangunan, karena mengintepretasikan kondisi bawah permukaan daerah yang diukur. Apabila nilai frekuensi dominan struktur bangunan sama dengan nilai frekuensi dominan daerah tersebut, maka ketika terjadi gempabumi akan terjadi resonansi. Resonansi tersebut akan memperkuat amplitude getaran gempabumi, sehingga berakibat kerusakan bangunan yang berada diatasnya saat terjadi gempabumi. Persebaran nilai frekuensi dominan di Kampus I Universitas PGRI Yogyakarta berkisar antara $1,27 \mathrm{~Hz}$ sampai $2,79 \mathrm{~Hz}$ yang dapat dilihat pada Gambar 3.

Dari gambar 3 menunjukkan nilai persebaran frekuensi dominan rendah ditunjukkan dengan warna hijau yang berada di titik UPY-01, UPY-02, UPY-03, UPY-04, UPY-09, UPY-10, dan UPY-14 yang berada di kawasan gedung $A$ yang merupakan gedung rektorat dan kawasan gedung $C$ yang merupakan gedung perkuliahan fakultas akutansi dan manajemen. Persebaran nilai frekuensi dominan sedang ditunjukkan dengan warna kuning berada di sebelah barat yang merupakan kawasan gedung fakultas Sains dan Teknologi dan timur daerah pengukuran yang merupakan kawasan gedung perpustakan dan auditorium Kampus Universitas PGRI Yogyakarta. Persebaran nilai frekuensi dominan tinggi ditunjukkan dengan warna merah yang berada di titik UPY-05, UPY-06, dan UPY11 kawasan gedung $B$ yang merupakan ruang laboratorium sejarah, laboratorium komputer dan kawasan parkir kendaraan. Peta persebaran nilai frekuensi dominan ditunjukkan pada gambar 3 dibawah ini.

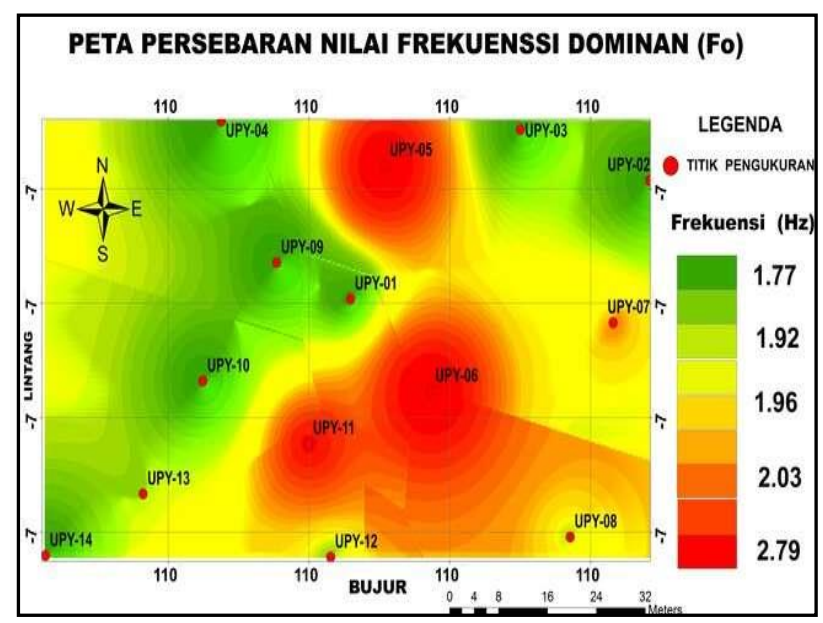

Gambar 3. Peta persebaran nilai frekuensi dominan $\left(f_{0}\right)$

\section{Amplifikasi (Ao)}

Perbedaan yang sangat kontras antar lapisan yang dilalui gelombang seismik akan mengakibatkan perbesaran gelombang, hal ini disebut dengan amplifikasi. Pada gelombang seismik akan terjadi amplifikasi apabila merambat dari medium satu ke medium lain yang lebih lunak dibandingkan dengan medium awal yang dilaluinya. Dari hasil pengukuran di kawasan Kampus I PGRI Yogyakarta diperoleh persebaran nilai amplifikasi $\left(A_{0}\right) 1.28$ sampai dengan 2,05 yang disajikan pada Gambar 4.

Suharna (2009) mengklasifikasikan besarnya faktor amplifikasi menjadi beberapa tingkatan sebagai berikut:

Tabel 1. Klasifikasi tingkat amplifikasi (Suharna, 2009)

\begin{tabular}{ccc}
\hline $\begin{array}{c}\text { Tingkat } \\
\text { amplifikasi }\end{array}$ & $\begin{array}{c}\text { Tingkat } \\
\text { kerawanan }\end{array}$ & $\begin{array}{c}\text { Makna } \\
\text { amplifikasi }\end{array}$ \\
\hline$<3$ & 1 & Rendah \\
\hline $3-6$ & 2 & Menengah \\
\hline $6-9$ & 3 & Tinggi \\
\hline$>9$ & 4 & Sangat tinggi \\
\hline
\end{tabular}

Berdasarkan klasifikasi pada Tabel 1. di atas, terlihat bahwa kawasan Kampus I Universitas PGRI Yogyakarta masuk ke dalam kategori amplifikasi rendah. Dari hasil 14 titik pengukuran nilai terendah 
ditunjukkan dengan warna coklat yang berada di titik pengukuran UPY-11 yang merupakan kawasan parkir kendaraan. Nilai amplifikasi tertinggi ditunjukkan dengan warna biru yang berada di titik pengukuran UPY-02 dan UPY-06 yang merupakan kawasan gedung $C$ yang digunakan untuk fakultas Manajemen dan Akutansi. Nilai amplifikasi yang tinggi menyebabkan tingkat kerusakan bangunan lebih besar pada saat terjadi gempabumi. Peta persebaran nilai amplifikasi ditunjukkan pada gambar 4 dibawah ini.

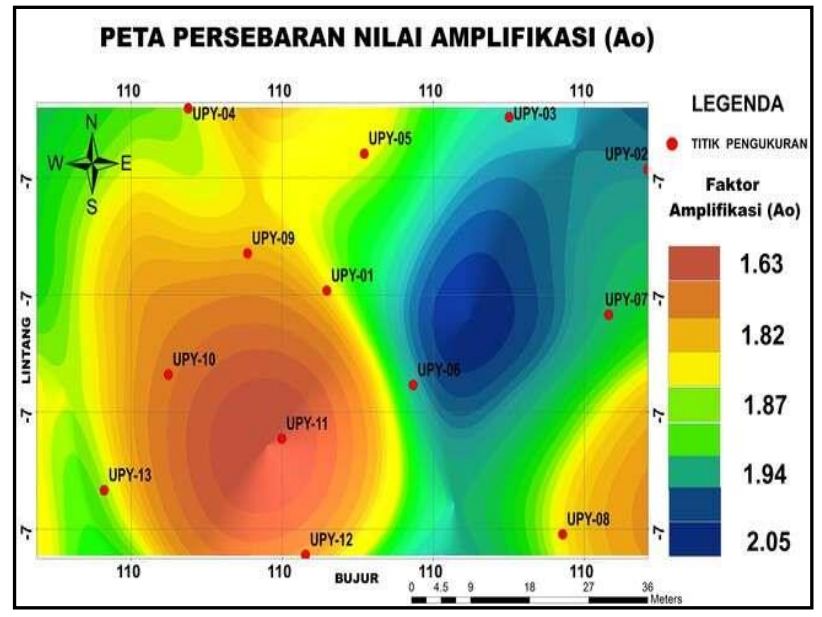

Gambar 4. Peta persebaran nilai Amplifikasi $\left(A_{0}\right)$

\section{Indeks Kerentanan Seismik $(\boldsymbol{K g})$}

Nilai indeks kerentanan seismik menggambarkan tingkat kerusakan tanah dan bangunan pada saat terjadi gempabumi. Nilai indeks kerentanan seismik pada suatu titik ditentukan dari nilai amplifikasi dan frekuensi dominan. Indeks kerentanan seismik berhubungan dengan tingkat kerusakan rumah akibat gempabumi, dimana dengan indeks kerentanan seismik 21,2 berhubungan dengan rasio kerusakan rumah sebesar $77 \%$ dan nilai indeks kerentanan seismik 8,0 berhubungan dengan rasio kerusakan rumah sebesar 48\% (Daryono, 2011). Nilai indeks kerentanan seismik di peroleh dari persamaan (4), selanjutnya dibuat peta kontur persebaran kerentanan seismik. Hasil pengukuran di kawasan Kampus I Universitas PGRI Yogyakarta di tunjukkan oleh gambar 5.

Dari hasil pengukuran indeks kerentanan seismik $(K g)$ yang ditunjukkan pada gambar 5 daerah dengan nilai rendah ditunjukkan dengan warna hijau yang merupakan kawasan parkir kendaraan. Untuk persebaran nilai indeks kerentanan seismik sedang ditunjukkan dengan warna kuning yang lokasinya menyebar diantara gedung $A$ yang merupakan gedung rektorat dan sebagian berada di kawasan gedung perpustakaan dan auditorium. Nilai persebaran tinggi ditunjukkan dengan warna merah yang berada di titik pengukuran UPY-02, UPY-03, dan UPY-04 yang berada di sekitaran gedung $C$ yang merupakan kawasan fakultas manajemen dan akutansi, dan sebagian berada di daerah antara gedung $B$ dan gedung $A$. Semakin tinggi nilai indeks kerentanan seismik menunjukkan lapisan sedimen tebal yang menandakan kondisi tanah pada daerah tersebut lebih rentan terhadap bencana gempabumi.

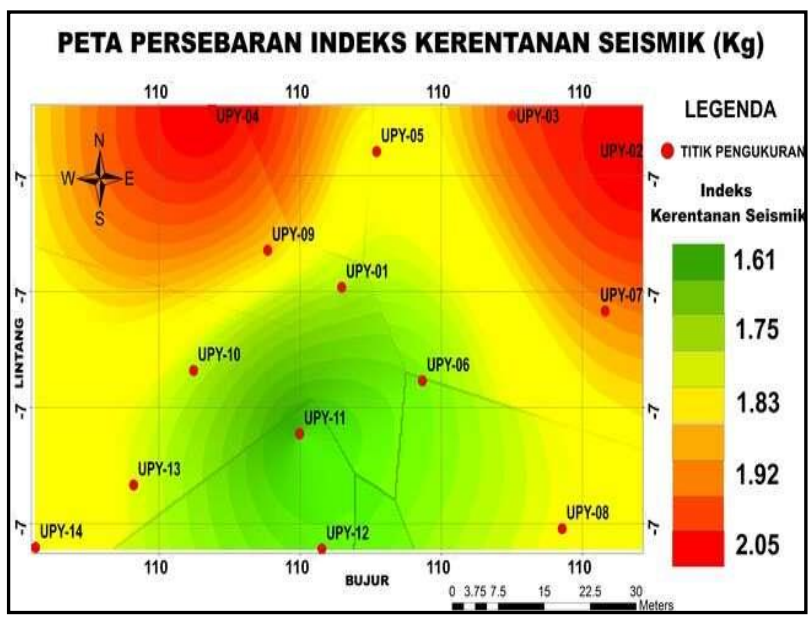

Gambar 5. Peta persebaran nilai Indeks Kerentanan Seismik $(K g)$

\section{Percepatan Getaran Tanah Maksimum (PGA)}

Nilai percepatan tanah maksimum didapatkan berdasarkan data gempabumi Yogyakarta 27 mei 2006 dengan koordinat -7.96 LS dan 110.44 BT kedalaman $12500 \mathrm{~m}$, dengan magnitude 6.3 Richter. Nilai PGA di lapisan permukaan selain dipengaruhi oleh magnitudo gempabumi, kedalaman, dan jarak episenter, juga dipengaruhi oleh nilai periode dominan. Pada metode Kanai selain parameter gempabumi, nilai periode dominan mempunyai fungsi pengontrol sehingga besarnya percepatan tanah akan dipengaruhi faktor geologi setempat yang terwakilkan oleh nilai periode dominan tanah. Nilai PGA di lapisan permukaan dapat diklasifikasikan menjadi 10 macam tingkatan risiko dan intensitas yang disajikan pada Tabel 2. 
Tabel 2. Tingkat risiko gempabumi (Fauzi, dkk., 2005)

\begin{tabular}{llcc}
\hline No & \multicolumn{1}{|c}{ Tingkat Risiko } & $\begin{array}{r}\text { Nilai } \\
\text { PGA } \\
\text { (gal) }\end{array}$ & $\begin{array}{c}\text { Intensitas } \\
\text { (MMI) }\end{array}$ \\
\hline 1. & Risiko sangat kecil & $<25$ & $<$ VI \\
\hline 2. & Risiko kecil & $25-50$ & VI-VII \\
\hline 3. & Risiko sedang 1 & $50-75$ & VII-VIII \\
\hline 4. & Risiko sedang 2 & $75-100$ & VII-VIII \\
\hline 5. & Risiko sedang 3 & $100-125$ & VII-VIII \\
\hline 6. & Risiko besar 1 & $125-150$ & VIII-IX \\
\hline 7. & Risiko besar 2 & $150-200$ & VIII-IX \\
\hline 8. & Risiko besar 3 & $200-300$ & VIII-IX \\
\hline 9. & Risiko sangat besar & $300-600$ & IX-X \\
& 1 & & \\
\hline 10. & Risiko sangat besar & $>600$ & $>\mathrm{X}$ \\
& 2 & & \\
\hline
\end{tabular}

Intensitas adalah suatu ukuran hasil pengamatan visual pada suatu tempat akibat goncangan selama gempabumi terjadi. Goncangan yang terjadi saat terjadi gempabumi dan persepsi manusia terhadap gempabumi dapat digambarkan melalui nilai intensitas. Skala intensitas yang digunakan adalah skala Modified Mercalli Intensity (MMI) seperti ditunjukkan pada Tabel 3.

Tabel 3. Skala Modified Mercalli Intensity (MMI)

\begin{tabular}{ccl}
\hline No & $\begin{array}{c}\text { Skala } \\
\text { Intensitas }\end{array}$ & $\begin{array}{l}\text { Efek terhadap infrastruktur, } \\
\text { lingkungan, dan manusia }\end{array}$ \\
\hline 1. & I & $\begin{array}{l}\text { Terjadinya getaran tapi tidak } \\
\text { terasa kecuali saat kondisi luar } \\
\text { biasa dari segelintir orang. }\end{array}$ \\
\hline 2. & II & $\begin{array}{l}\text { Terjadinya getaran terasa dari } \\
\text { segelintir orang, dan benda- } \\
\text { benda ringan yang tergantung } \\
\text { akan bergoyang. }\end{array}$ \\
\hline 3. & III & $\begin{array}{l}\text { Terjadinya getaran terasa } \\
\text { nyata di rumah, dirasakan } \\
\text { getaran seperti ada mobil/truk } \\
\text { melintas. }\end{array}$ \\
\hline 4. & IV & $\begin{array}{l}\text { Jika terjadi siang hari terasa } \\
\text { dari orang-orang yang berada } \\
\text { di dalam rumah dan di luar } \\
\text { rumah, jendela, atau pintu } \\
\text { gemerincing. }\end{array}$ \\
\hline $\mathbf{5 .}$ & V & $\begin{array}{l}\text { Terjadinya getaran terasa oleh } \\
\text { semua orang, gerabah pecah, }\end{array}$ \\
\hline
\end{tabular}

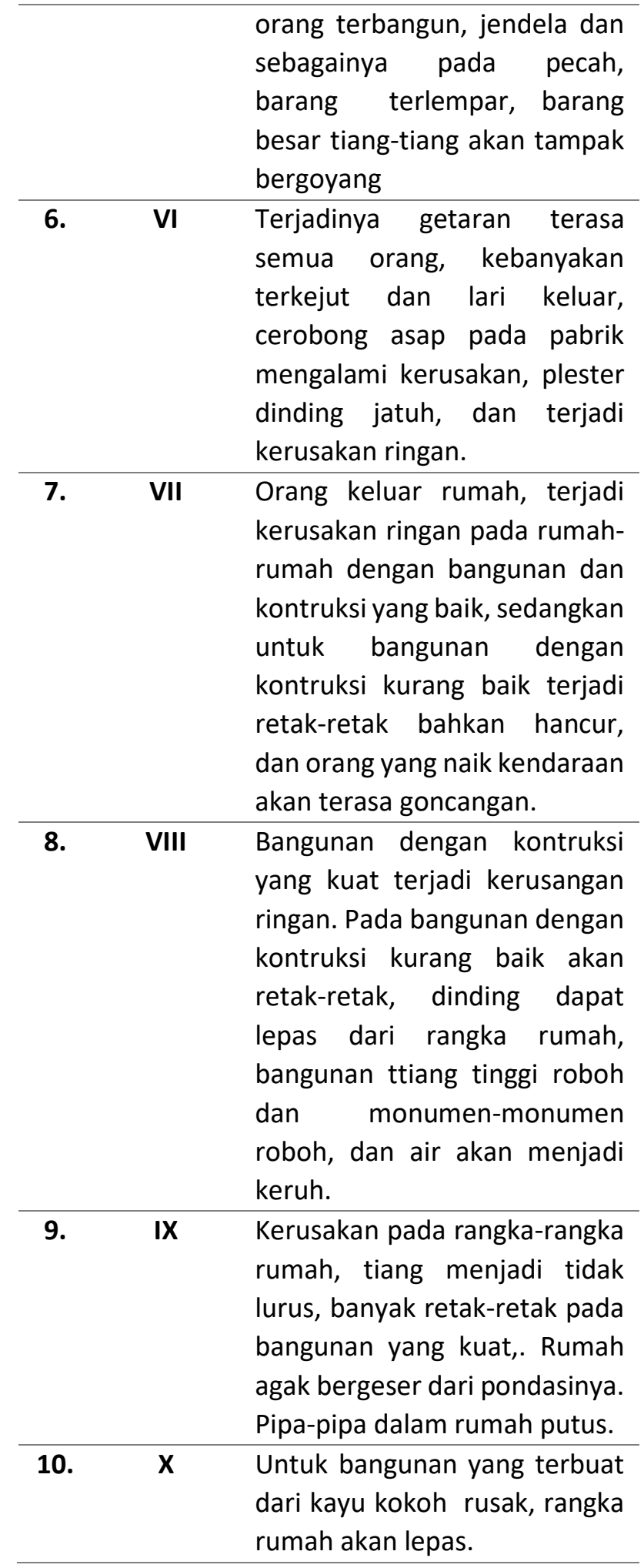

Dari hasil pengukuran nilai PGA dilapisan permukaan yang ditunjukkan pada Gambar 6 didapatkan nilai PGA berkisar antara 82.04 gal sampai dengan 184.62 gal yang ditunjukkan dengan warna biru yang berada di sebelah Barat yang merupakan gedung Saintek. Nilai PGA 184.63 gal sampai dengan 207.67 gal ditunjukkan dengan 
warna kuning, dan nilai PGA 207.70 gal sampai dengan 236.84 gal yang di tunjujkkan dengan warna merah yang berada di titik UPY-05 dan UPY-06 yang merupakan kawasan perpustakaan dan auditorium1. UPY. Dari hasil pengukuran jika dikorelasikan dengan klasifikasi analisis tingkat risiko dan2. intensitas gempabumi masuk ke dalam tingkat resiko sedang dua sampai dengan risiko besar tiga dengan intensitas VII-IX MMI seperti yang ditunjukkan pada tabel 2 .

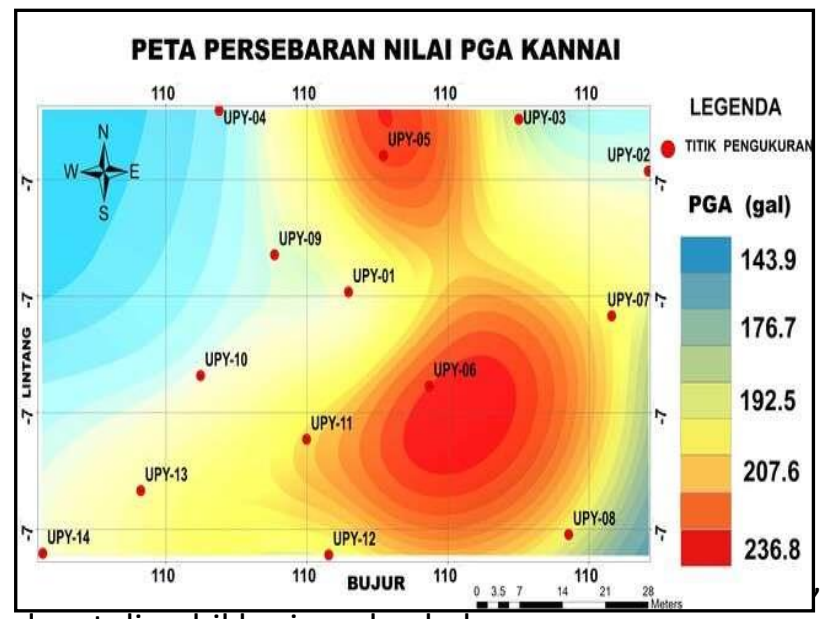

dapat diambil kesimpulan bahwa:

1. Nilai frekuensi dominan di kawasan Kampus I Universitas PGRI Yogyakarta berkisar antara $1,27 \mathrm{~Hz}$ sampai dengan $2,79 \mathrm{~Hz}$ dan diperoleh persebaran nilai amplifikasi 1.28 sampai dengan 2,05. Nilai frekuensi dominan $\left(f_{0}\right)$ tinggi mengindikasikan adanya lapisan sedimen yang tipis. Nilai frekuensi dominan $\left(f_{0}\right)$ rendah menunjukkan adanya lapisan sedimen lunak yang tebal, sehingga sangat mempengaruhi bahaya getaran periode panjang yang dapat mengancam gedunng-gedung bertingkat.

2. Nilai indeks kerentanan seismik tertinggi berada berada di sekitaran gedung $\mathrm{C}$ yang merupakan kawasan fakultas manajemen dan akutansi, sehingga lebih rentan apabila terjadi bencana gempabumi.

3. Nilai PGA dilapisan permukaan berkisar antara 82.04 gal samapi dengan 236.84 gal yang masuk ke dalam golongan tingkat resiko sedang dua sampai dengan risiko besar tiga dengan intensitas VII-IX MMI yang sebagian besar berada di area gedung perpustakaan dan auditorium UPY.

\section{Saran}

Saran yang dapat diperoleh dari hasil pembahasan penelitian ini dalam rangka membangun hipotesahipotesa selanjutnya, antara lain:

Perlu di tambahkan titik pengukuran mikroseismik di kawasan Kampus II dan Kampus III UPY.

Perlu dilakukan penelitian lebih lanjut tentang analisa tingkat kerentanan dan resiko akibat bahaya gempabumi dikarenakan banyak sekali gedunggedung baru di lingkungan kampus UPY.

\section{Ucapan Terima Kasih}

Penulis mengucapkan terima kasih kepada segenap keluarga besar Universitas PGRI Yogyakarta, khususnya Fakultas Sains dan Teknologi dan Program Studi Teknologi Rekayasa Elektromedis yang telah membantu dalam proses pengambilan dan penganalisis data dalam penelitian ini.

\section{DAFTAR PUSTAKA}

A. Wulandari, S. Suharso, R. Rustadi, dan R.R. (2016), "MICROZONATION MAPPING THE PRONE EARTHQUAKE AREAS OF", Jurnal Geofisika Eksplorasi, Vol.4, No.1, hal. 33-48.

Brotopuspito, K. (2006), "Percepatan Getaran Tanah Maksimum Daerah Istimewa Yogyakarta 19432006", Jurnal Geofisika, Vol.1, hal. 19-22.

C. Sulaeman, L. Cendekia Dewi, W.T. (2008), "Karakterisasi Sumber Gempa Yogyakarta 2006 Berdasarkan Data GPS", Indonesian Journal on Geoscience, Vol.3.

Daryono, Sutikno, J.S. dan K.S.B. (2009), "Pengkajian Local Site Effect di Graben Bantul Menggunakan Indeks Kerentanan Seismik Berdasarkan Pengukuran Mikrotremor", Jurnal Kebencanaan Indonesia, Vol.2, No.1.

Gunawan, A. dan Khadiyanto, P. (2012), "Kajian Aspek Bentuk Lahan dan Geologi Berdasarkan Mikrotremor dalam Perencanaan Ruang Kawasan Rawan Gempa di Kabupaten Bantul Daerah Istimewa Yogyakarta ( Studi Kasus: Kecamatan Bantul , Jetis , Imogiri , dan Kretek )", Biro Penerbit Planologi Undip, Vol.8, No.2, hal. 178-190.

Haifani, A.M. (2008), manajemen resiko bencana gempa bumi (studi kasus gempa bumi yogyakarta 27 mei 2006), Yogyakarta, hal. 25-26,.

Hakim, A.C., Pramono, S., Warnana, D.D., Rochman, J.P.G.N. dan Rahmatullah, F.S. (2019), "Determination of Ground Profile and Peak Surface Acceleration (PSA) Using Single Station Microtremor Inversion Method for Earthquake Hazard Zonation of Lombok Island", IOP 
Conference Series: Earth and Environmental

Science, Vol.389, hal. 012045.

http://doi.org/10.1088/1755-

1315/389/1/012045.

Hidayat, S., Warnana, D.D., Koesuma, S., Fisika, I., Maret, U.S., Ir, J., Kentingan, S.A. dan Tengah, J. (2017), "Aplikasi Metode Horizontal to Vertical Spectral Ratio Pada Perhitungan Frekuensi Natural dan Amplitudo HVSR", Prosiding Pertemuan IImiah XXXI HFI Jateng \& DIY, hal. 105-109.

Kanai, K. (1983), Seismology in Engineering, Tokyo University, Tokyo, Japan.

Marjiyono (2010), Estimasi Karakteristik Dinamika Tanah Dari Data Mikrotremor Wilayah Bandung, ITB, Bandung.

Mucciarelli, M. (2015), A critical review of 10 years of microtremor HVSR technique, No.November.

Nakamura, Y. (2000), Clear Identification of Fundamental Idea of Nakamura's Technique and its Application, World Conference of Earthquake Engineering,

Sesame (2004), Guidelines for the Implementation of The $H / V$ Spectral Ratio Technique on Ambient Vibrations, European Commision.

Setiyono (2018), Katalog Gempa Bumi Signifikan dan Merusak 1821 - 2017, Jakarta.

Tanjung, N.A.F., Yuniarto, H.P. dan Widyawarman, D. (2019), "Analisis Amplifikasi Dan Indeks Kerentanan Seismik Di Kawasan Fmipa Ugm Menggunakan Metode HVSR", Jurnal Geosaintek, Vol.5, No.2, hal. 61-68-68. http://doi.org/10.12962/j25023659.v5i2.5726.

Zona, P., Guncangan, R., Gempa, B., Liwa, D., Sekitarnya, D.A.N., Arifin, S.S., Mulyatno, B.S. dan Setianegara, R. (n.d.), Hindia- Geologi Regional Wilayah Penelitian yang didominasi perbukitan, Vol.2, No.1. 